\title{
La representación del fotoperiodista en el cine del siglo XX: fotógrafos en lugares de conflictos y sensacionalistas
}

\section{Fotokazetariak XX. mendeko zineman: gatazka- guneetako argazkiak eta sentsazionalismoa}

\section{The image of the photojournalists in the XXth century films: conflict and tabloid photographers}

\section{Olga Osorio ${ }^{1}$}

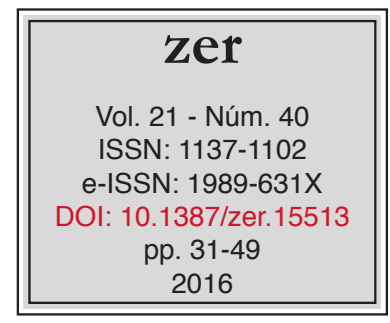

Recibido el 28 de julio de 2015, aceptado el 26 de noviembre de 2015.

\section{Resumen}

A través de un análisis de 107 películas estrenadas en España entre 1928 y 2000 en las que aparecen un total de 122 fotoperiodistas y/o operadores de cámara como personajes destacados, se realiza un retrato robot de los rasgos más reiterados en la representación cinematográfica de este tipo de personaje, del que se analizan con más detalle los dos estereotipos dominantes: el enviado especial a lugares en conflicto que predomina de los años 80 y los más amorales caza-exclusivas a través de sus distintos subtipos.

Palabras clave: Fotoperiodistas, análisis de contenido, películas, siglo XX, identidad periodística.

\section{Laburpena}

Espainian 1928. eta 2000. urteen artean argitaratutako 107 film aztertu dituzte. Film horietan, guztira 122 fotokazetari edo kamerari ageri dira pertsonaia garrantzitsuen rolak antzezten. Azterketa horretatik ateratako ondorioekin, erretratu-robot bat egin dute, mota horretako pertsonaiek filmetan izan ohi dituzten ezaugarriekin. Hortik abiatuta, sakonago aztertu dira bi estereotipo nagusi hauek: 80ko hamarkadan nagusi den gatazka-guneetako berriemaile berezia, alde batetik, eta moralik gabeko esklusiba-ehiztariak, eta horien azpimotak, bestetik.

\footnotetext{
Universidade da Coruña, olga.osorio@udc.es
} 
Gako-hitzak: Fotokazetariak, eduki analisia, filmak, XX. mendea, kazetariaren identitatea.

\begin{abstract}
Through a content analysis of 107 films released in Spain between 1928 and 2000 which portrayed a total of 122 photojournalists and / or camera operators as prominent characters, we draw a composite sketch with the most repeated features in this type of character representation and we discuss in more detail the two dominant stereotypes: the conflict photographer that dominated the 80s and the most amoral-exclusive hunting through its various subtypes.
\end{abstract}

Keywords: Photojournalists, content analysis, films, 20th century, journalistic identity. 


\section{Introducción}

El relato cinematográfico, tal y como se concibe desde el punto de vista comercial, propicia la utilización de personajes y situaciones estereotipadas que facilitan un rápido reconocimiento e identificación por parte del público. Los matices, que consumen tiempo de relato, son a menudo sacrificados en aras del dinamismo narrativo, por lo que se suele recurrir a personajes que presentan cuatro o cinco rasgos esquemáticos fácilmente reconocibles por el público y que suelen ser coherentes y repetitivos entre sí. Esta característica narrativa tiene una importante dimensión sociológica e ideológica, desde el momento en que la simplificación permite detectar las ideas dominantes en la sociedad en un momento determinado sobre un determinado colectivo, ideas que el cine recoge al tiempo que genera y fortalece.

La relación entre cine y periodismo ha sido intensa desde los propios orígenes del medio cinematográfico y son muchos también los estudios que desde el ámbito académico o divulgativo se han ocupado de ella. Osorio (2009: 12-32) hace un repaso exhaustivo sobre el estado del arte hasta 2009 en su tesis doctoral sobre la representación de las periodistas en el cine del siglo XX. Desde entonces hasta la fecha el tema parece haber sido objeto de renovado interés, lo que ha motivado en el ámbito hispano-hablante la publicación de tres libros: una monografía divulgativa de Mínguez Santos sobre la imagen de los periodistas en el cine (2012), una recopilación de trabajos coordinada por Beatriz Pérez Acuña (2013) y un estudio específico sobre la representación de los periodistas en el cine de Billy Wilder (Peña, 2014), nacido de la tesis doctoral del autor (2011) sobre el mismo asunto. Asimismo, el grupo de investigación dirigido por Ofa Bezurnatea publicó cinco nuevos artículos sobre el tema, que fue asimismo protagonista de trabajos de fin de grado y fin de máster en diversas universidades y de algunos artículos en revistas de investigación, entre los que a efectos de este artículo destaca el trabajo de Nekane Parejo (2009) sobre los reporteros de guerra en el cine. En el ámbito anglosajón sobresalen dos monografías: Journalists in films plantea el análisis de los periodistas cinematográficos desde la dualidad de su presentación como héroes o villanos (McNair, 2010), un enfoque muy similar al de Heroes and Scoundrels: The Image of the Journalist in Popular Culture (The History of Communication) (Ehrlich \& Saltzman, 2015).

En lo que respecta a los fotoperiodistas en particular, el corpus bibliográfico es mucho más escaso, por no decir prácticamente inexistente, y se limita a una tesis de la Universidad de Missouri (McDaniel, 2007). Ahondando en este ámbito, el objetivo del presente artículo es analizar los estereotipos dominantes en su retrato dentro del relato cinematográfico a lo largo del siglo XX con el objetivo de identificar la consideración social que reciben estos profesionales de la información a través de su retrato fílmico y de confirmar o desestimar la hipótesis de partida de que los fotógrafos de prensa son para el cine casi exclusivamente varones de raza blanca retratados con matices heroicos.

\section{Metodología y fuentes}

El análisis propuesto se basa en el visionado de 107 películas en las que aparece algún personaje de fotoperiodista con un papel relevante (protagonistas, coprotagonistas 
o secundarios con frase), estrenadas a lo largo del siglo XX (entre 1928 y 1999) en España. Para elaborar dicho listado se llevó a cabo un vaciado de la bibliografía específica sobre cine y periodismo, en especial, el exhaustivo trabajo de Richard Ness (1997), que cubre desde los orígenes del cine hasta 1996. La consulta a cuatro bases de datos (IJPC, Filmaffinity, IMDB y base de datos de Películas Calificadas del Ministerio de Educación, Cultura y Deportes), unida a la bibliografía específica mencionada, constituyó el principal recurso junto con el repertorio bibliográfico y filmográfico publicado en la red por la biblioteca de la Universidad de Berkeley (University of California, Berkeley, 1996-2009).

A partir de un visionado de las mencionadas películas se obtiene un listado de 122 personajes, entre los que se incluyen fotógrafos y/o operadores de cámara que aparecen en papeles protagonistas, coprotagonistas y/o secundarios con frase. A partir de este listado se hace una reflexión global sobre el modo en que se ha representado a los fotoperiodistas y operadores de cámara atendiendo a las categorías dramáticas, sexo de los personajes y funciones laborales y si la representación es mayoritariamente positiva o negativa. Tras este análisis cuantitativo nos detenemos a continuación en dos categorías de análisis escogidas en función de su representatividad: los fotoperiodistas enviados especiales a conflictos bélicos y los fotógrafos de la prensa sensacionalista, que oscilan entre el heroísmo no demasiado eficaz del reportero de guerra y la amoralidad total del caza-exclusivas típico del periodismo amarillista.

\section{Gráfico 1. Sexo de los personajes de fotoperiodistas en el cine del siglo XX.}

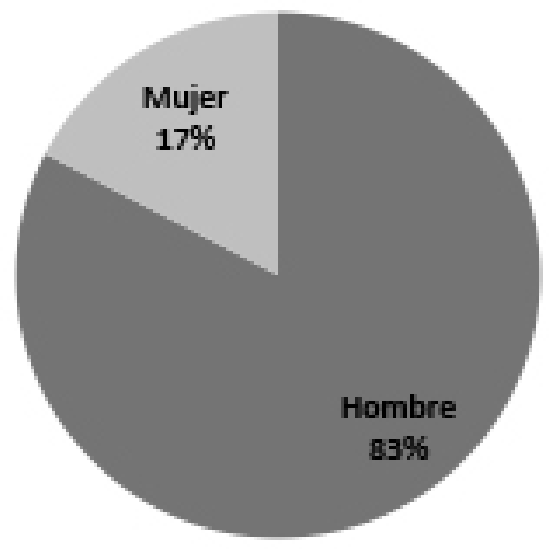

\section{Un trabajo masculino y poco cualificado}

Un primer elemento que salta a la vista al analizar la imagen del fotoperiodista y/o operador de cámara en el cine del siglo XX es que esta es principalmente masculina. De los 122 personajes analizados tan sólo 21 son femeninos, lo que supone un 17\% frente a un $83 \%$ de hombres (Gráfico 1). En contrapartida, los personajes femeninos parecen adquirir más protagonismo cuando están presentes y, así, hasta un 31,58\% de los protagonistas analizados son mujeres (Gráfico 3). El periodista del cine es 
además de raza blanca (82\%) frente a la minoritaria presencia de negros (12\%), latinos $(4 \%)$ y asiáticos $(2 \%)$ (Gráfico 2$)$.

Gráfico 2. Raza de los personajes de fotoperiodistas y operadores de cámara en el cine del siglo XX.

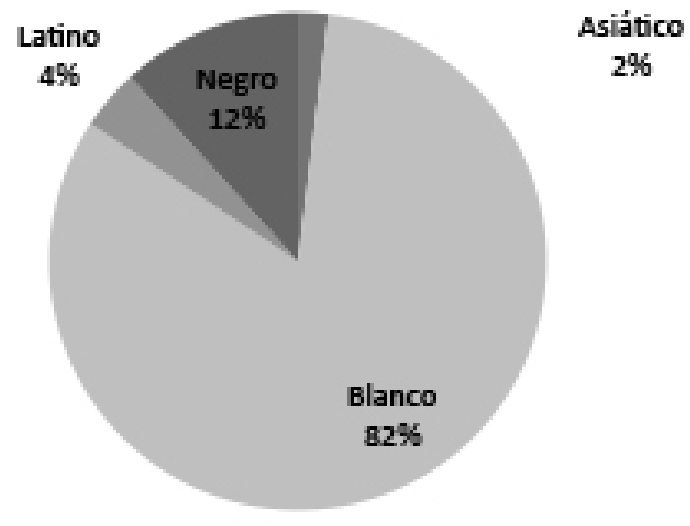

Gráfico 3. Porcentaje de fotoperiodistas masculinosy femeninos en función de su rol dramático.

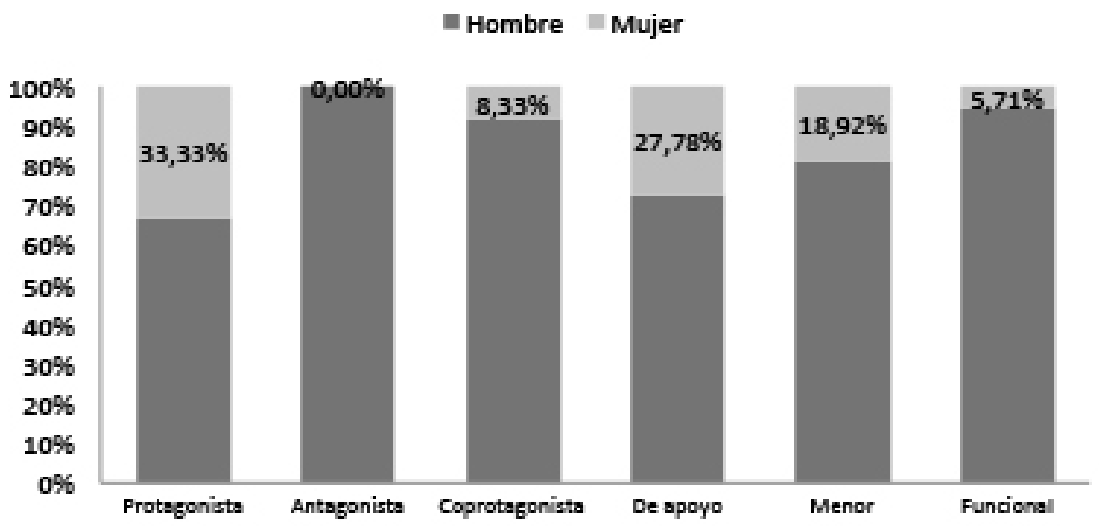

Continuando con este retrato robot general, 85 de los 122 personajes de fotoperiodistas son fotógrafos (70\%) y 36 operadores de cámara (30\%) (Gráfico 4). Estos datos permiten ya anticipar que la mayoría de los personajes analizados trabajan para medios escritos. Es significativo también observar que donde menos personajes femeninos hay es precisamente en televisión o cine (Gráfico 5), lo que revela claramente el prejuicio cinematográfico a la hora de mostrar a personajes femeninos desarrollando labores técnicas, mientras que es más que habitual la imagen de la presentadora/ reportera de televisión acompañada de un operador de cámara.

En la misma línea, si nos centramos en el tipo de información que cubren estos personajes, veremos que en áreas tradicionalmente más femeninas como la moda encontramos una total ausencia de fotógrafas o cámaras mientras que sí las encontra- 
mos ejerciendo este tipo de trabajos en ámbitos más "masculinos" como los entornos bélicos (Gráfico 6), donde la presencia más o menos exótica de un periodista permite introducir a un personaje femenino (y con él no pocas veces una trama romántica). En términos generales, el tipo de información específica más abundante es la internacional, sobre todo si sumamos los apartados de información bélica e internacional propiamente dicha, seguida de los Sucesos.

Gráfico 4. Porcentaje de fotógrafos y operadores de cámara entre los personajes del cine del siglo XX.

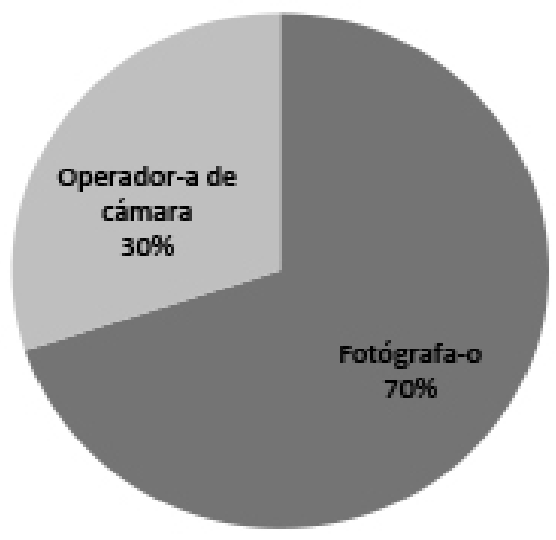

Gráfico 5. Medios para los que trabajan los personajes de fotoperiodistas y operadores de cámara del cine del siglo XX.

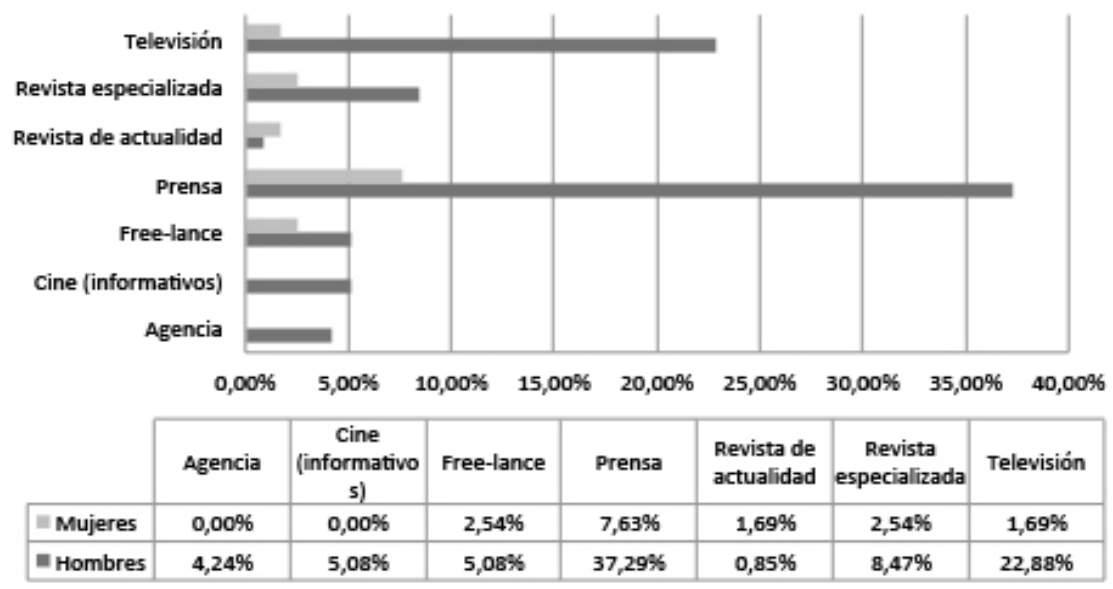

Finalmente, los fotoperiodistas cinematográficos suelen aparecer retratados en plena madurez, entre los 30 y los 50, en el caso de los personajes masculinos, mientras que los femeninos suelen ser mucho más jóvenes, menores de 30 en la mayoría de los casos y en la década de los 30 como mucho (Gráfico 7), en línea con los datos ya apuntados en las investigaciones realizadas en torno a los estereotipos masculinos y 
femeninos en los medios de comunicación que corroboran, de manera consistente, la idea de que la edad constituye uno de los rasgos en los que de manera más clara se aprecia el sexismo de la representación. Las mujeres que aparecen en los medios o bien son jóvenes, que es la opción más habitual, o bien, en el caso de que se rompa la norma, aparecen retratadas de forma negativa (Hart, 2008) o chocante mientras que, sin embargo, sus colegas o compañeros sentimentales son mucho mayores que ellas.

Gráfico 6. Tipo de información que cubren los personajes de fotoperiodistas y operadores del cine del siglo XX.

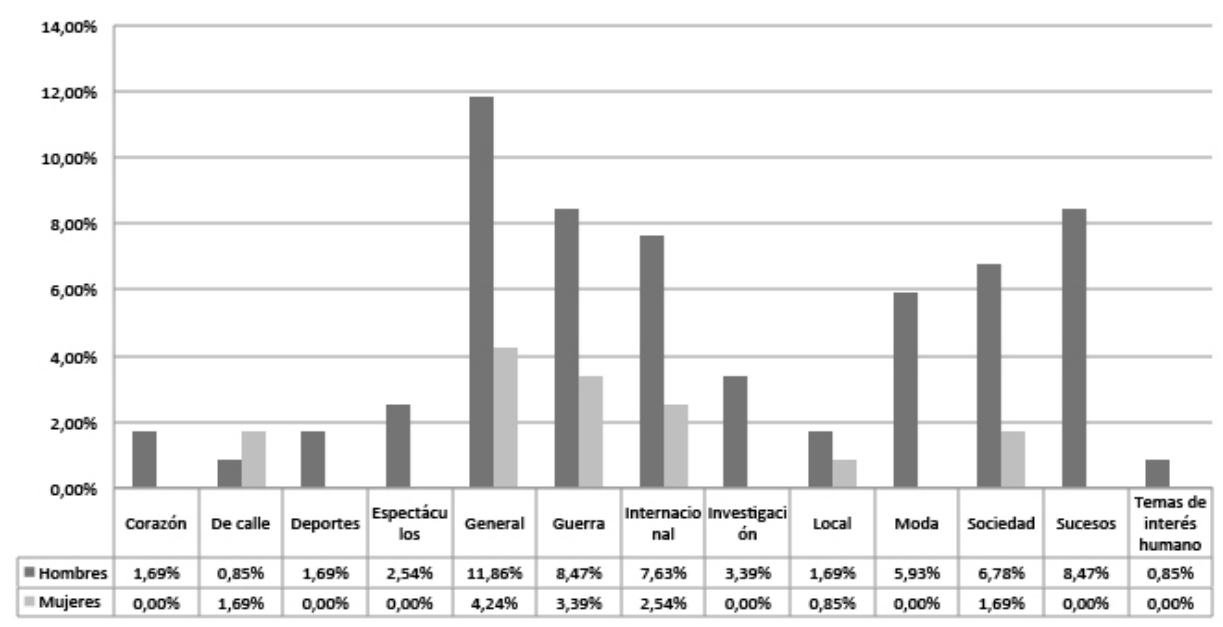

Gráfico 7. Franjas de edad de los personajes de fotoperiodistas y/o operadores en el cine del siglo XX.

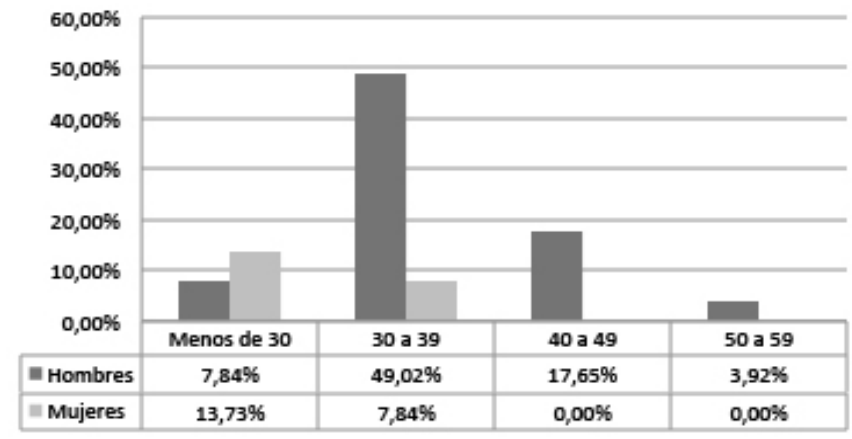

Otra cuestión genérica interesante es que los guionistas y cineastas no suelen hacer una distinción estricta entre el trabajo del periodista y el del fotógrafo, a excepción de estereotipos muy concretos como el operador de cámara como personaje secundario. Con esta salvedad, son numerosos los casos en que el periodista y el fotoperiodista son la misma cosa. No es raro ver a un reportero de prensa utilizando con soltura la cámara de fotos, ya sea de vez en cuando o de manera sistemática, de modo que las fronteras entre estas dos actividades profesionales, muy marcadas en la vida real, se desdibujan con frecuencia en su versión cinematográfica. 
Ejemplos significativos al respecto son Los Gritos del Silencio (Roland Joffé, 1984) o Salvador (Oliver Stone, 1986), en las que los reporteros ejercen también de fotógrafos, aunque en el primer caso el protagonista Sidney (Sam Waterson) se hace acompañar por uno de vez en cuando. En Salvador (Oliver Stone, 1986), Boyle (James Woods) escribe y fotografía, a diferencia de Cassidy (John Savage) que aparece retratado exclusivamente como fotógrafo. En Sucedió en China (Jack Conway, 1938), los dos protagonistas son a un tiempo operadores de cámara (de cine en este caso) y reporteros, y son varias las ocasiones en las que los vemos utilizando una cámara de fotos en lugar de una de cine, aunque el resultado de su trabajo siempre se muestra en forma de película.

Dos películas donde los medios de comunicación centran la trama como El gran carnaval (Billy Wilder, 1951) y Mad City (Constantin Costa-Gavras, 1997) muestran paradójicamente como encargados de hacer las fotos u operar la cámara de vídeo a los de "prácticas", los "novatos". En el caso de Laurie (Mia Kirshner) su carrera periodística es meteórica, ya que comienza el día (y la película) como ayudante de cámara para poco más tarde ir como operadora acompañando a Brackett (Dustin Hoffman) en una cobertura en la que, aparentemente, es también la encargada de establecer las conexiones mediante la unidad móvil. Cuando la noticia se vuelve más importante un operador de cámara la releva mientras ella empieza a ayudar a Brackett en calidad de reportera. A última hora del día, vestida ya con un traje de chaqueta rojo y micrófono en mano, cubre la noticia para la emisora. Más allá de este ascenso meteórico, el ejemplo de Laurie y el de Herby en El Gran Carnaval parece dejar claro que los cineastas no consideran demasiado especializado el trabajo del fotógrafo o del operador de cámara. También en el Detrás de la noticia (Ron Howard, 1994) entra en juego una fotógrafa novata y poco diestra que, contra todo pronóstico, logra llevar a buen puerto su cometido.

Quizá la conclusión no pueda ser otra que el inolvidable fragmento de El Cameraman (Edward Sedgwick, Buster Keaton, 1928), en el que tras las innumerables vicisitudes y meteduras de pata del aspirante a fotoperiodista Buster Keaton vemos la destreza de que hace gala un inesperado operador que no es otro que un avispado mono, tal vez un mensaje "subliminal" sobre las cualidades necesarias para ser un buen operador de cámara.

Una vez vistos estos rasgos genéricos los dos siguientes epígrafes están dedicados al repaso de los dos estereotipos más habituales durante el pasado siglo en la representación de los gráficos en el cine: el corresponsal de guerra y el sensacionalista fotógrafo de sucesos y/o sociedad, que constituyen los dos estereotipos repetidos en más películas y a los que al cine ha dedicado más atención a lo largo del siglo XX, en comparación con otros personajes también estereotipados como los operadores de cámara de televisión o las mujeres fotógrafas.

\section{El fotoperiodista corresponsal de guerra: el individuo frente a la maquinaria de la guerra}

El fotoperiodista de guerra constituye un personaje cinematográfico emblemático vinculado sobre todo a filmes de denuncia política estrenados en la década de los 80 . Estas películas, que giran alrededor a la figura de un protagonista duro y comprometido con 
la verdad y con su trabajo, plantean interesantes cuestiones relacionadas con el inédito escepticismo norteamericano respecto al rol de su país en los conflictos internacionales y en particular en el Tercer Mundo. A partir de Vietnam, el pueblo americano va a poner en duda su capacidad real como observador para saber qué es lo que está ocurriendo en realidad (Moberg, 1995). La figura del enviado especial, observador solitario y muchas veces carente de códigos para entender su entorno, resulta perfecta para reflejar este sentimiento colectivo y por ello en estos años se producen varios títulos importantes en el retrato cinematográfico del periodismo protagonizados por personajes que si no son reales están muy apegados a la realidad.

Under Fire is part of a subgenre of films that emerged in the 1980s dealing with American correspondents in Third World situations, but it expands on notions of individualism, the manipulation of truth by the media and the manipulation of the media itself by various social forces (Ness, 1997, p. 594).

Bajo el fuego (Roger Spottiswoode, 1983) narra la historia de tres periodistas norteamericanos durante el último periodo de la dictadura de Somoza en Nicaragua, cuando el Frente Popular Sandinista derribó al dictador en 1979. El protagonista, Russell Price, interpretado por Nick Nolte, es un fotógrafo que se va a enfrentar al dilema moral entre la neutralidad que constituye una de las normas básicas de la profesión periodística y la necesidad o posibilidad de tomar partido ante una situación injusta. Para Price el primer mandamiento del periodista es mantener la independencia y así lo defiende de manera explícita cuando un cura pro Frente Popular le pregunta de qué lado está. "De ninguno, soy fotógrafo" (00:27:12). Sin embargo, diversos acontecimientos irán demostrándole lo difícil que es mantener esta neutralidad por la que aboga. Por ejemplo, cuando asiste al asesinato de un joven guerrillero con el que conversa sobre béisbol, abatido a sangre fría por un militar al que él mismo poco antes ha visto ocultarse. El momento hace mella en el ánimo del fotógrafo, que empieza a experimentar en carne propia que no intervenir también tiene conscuencias inmediatas y brutales.

Finalmente, llega el momento en que Price se plantea si debe o no utilizar su cámara como arma para ayudar a los guerrilleros que luchan contra el dictador Somoza -que cuenta con el apoyo de la CIA- accediendo a su petición de retratar al recientemente abatido líder de la insurrección (Rafael) como si aún estuviera vivo. Se plantea así el dilema de si es más moral difundir la verdad, aunque implique la pérdida de vidas y la victoria de una causa injusta, o falsearla para evitar males mayores y ponerse así de parte de la justicia. "Ellos decidirán actuar como personas y no como profesionales del periodismo" (Castellano Montero, 1994: 18) o, dicho de otro modo, accederán a la petición de los insurgentes, contribuyendo a dar forma a una mentira. Irónicamente, no es el acto de Nolte sino el asesinato de Alex Grazier ${ }^{2}$ (Gene Hackman) el que motiva que Estados Unidos retire su apoyo crucial, empujado por la indignación del público americano al ver lo sucedido en televisión: "Han muerto 500.000 nicaragüenses y ahora un yanqui (...) Quizá deberíamos haber matado a un

2 Inspirado en la muerte real del periodista Bill Stewart. 
periodista americano hace 50 años" (01:58:07), le dice una nicaragüense a la llorosa periodista mientras escuchan la noticia por televisión, poniendo en evidencia que no todos los muertos valen lo mismo.

Si en Bajo el fuego el asesinato de un periodista logra desatascar una situación injusta, en Salvador nada parece tener el más mínimo poder para cambiar los acontecimientos. "Tienes que acercarte para capturar la verdad. Si te acercas demasiado te mueres", dice Cassidy en uno de los momentos más significativos de la película desde el punto de vista del retrato del fotoperiodista, cuando ambos visitan el campo de cadáveres de "El Playón" (00:29:03). Esta afirmación constituye un anticipo de su propia muerte, que ocurre cuando intenta fotografiar un bombardero. El fotógrafo agonizante encarga a su compañero que lleve a Nueva York la toma que por fin ha conseguido, dejándose la vida en el intento. John Cassidy representa al periodista que ama su trabajo más que a su propia vida frente a la actitud más cínica y vividora de su amigo y protagonista, Richard Boyle (James Woods), quien va a empezar a tomarse más en serio su trabajo como periodista y los acontecimientos que están ocurriendo en El Salvador tras ser testigo del asesinato del arzobispo Romero y de la muerte de su compañero. Boyle traza un plan para sacar a su novia salvadoreña del país pero María y sus dos hijos son detenidos ante un impotente Boyle que le grita al policía una y otra vez: "No sabe lo que ocurre en El Salvador, no tiene ni idea" (01:57:09). Con esta frase que refleja su tragedia personal, el periodista le está indirectamente contando al espectador lo futil de su trabajo y lo imposible que es transmitir el horror de la guerra y las atrocidades que genera a todos aquellos que no los han vivido. Ni la muerte de Romero de la que él ha sido testigo ni el sacrificio de Cassidy por sus fotos lograrán cambiar nada ${ }^{3}$.

Por su parte el australiano Guy Hamilton (Mel Gibson) se enfrenta en El año que vivimos peligrosamente (Peter Weir, 1982) a un conflicto entre lo personal y lo profesional. Frente al retrato heroico de los periodistas en las películas de la Segunda Guerra Mundial, los filmes de los 80 ponen de relieve la falta de comprensión por parte de los informadores de la realidad del país en que se encuentran, que en este caso es Indonesia. En esta película es el fotógrafo Billy Kwan (Linda Hunt), quien representa la necesidad de tomar partido y actúa como conciencia del novato Hamilton, quien tiene que poner en una balanza el respeto a la información obtenida off the record a través de su amante y la necesidad de hacer pública una entrega de armas. Billy Kwan representa además un tipo de personaje bastante habitual en este grupo de películas sobre enviados de guerra: el indígena que sirve de suerte de intérprete local al periodista extranjero y le ayuda a entender no sólo el lenguaje sino sobre todo la cultura y los códigos éticos del país en el que se encuentran.

Dith Pran (Haing S. Ngor) es su equivalente en Los gritos del silencio ${ }^{4}$, en la que Sidney Schanberg (Sam Waterson) es un periodista de The New York Times que viaja a Camboya como corresponsal de guerra y que como Hamilton va a demostrar su

\footnotetext{
3 La película presenta los hechos que narra como reales y de hecho incorpora unas cartelas finales que informan de la suerte de los protagonistas tras los hechos relatados por el filme, entre ellos de la publicación de las fotos de John Cassidy. Sin embargo este personaje, a diferencia de Boyle, María o Romero, sólo existió en la ficción. Por otra parte no es cierto que, como se cuenta en la película, Boyle hubiese sido testigo del asesinato de Romero (von Tunzelmann, 2009).

4 Basada en hecho reales.
} 
incapacidad para comprender la cultura del país en que se halla, una sensación que la forma narrativa del filme refuerza dejando que la secuencia en la que Dith Pran negocia su liberación con los "Jemeres Rojos" transcurra en camboyano sin subtítulos. Al igual que los periodistas, los espectadores sólo podemos tratar de deducir que ocurre y confiar en la capacidad de Pran como negociador e intérprete.

Dith Pran queda retenido en Camboya con riesgo para su vida, mientras los demás regresan a sus países de origen. Ya en Estados Unidos, Schanberg recibe un premio por su trabajo que recoge con amargura, consciente de la participación de Estados Unidos en los sucesos que ha reportado y de su propia responsabilidad. Justo a continuación uno de sus colegas le reprocha haber abandonado a Pran para ganar un premio (01:46:22). Schanberg se defiende alegando que "esto no es una peli de los 40, no puedes meterte en un avión y cambiar el mundo", en línea con el ya mencionado escepticismo de estas películas con respecto al poder de los individuos y de la prensa para modificar de manera efectiva la realidad.

Si los periodistas de Bajo el fuego deciden manipular la información y el de Los años que vivimos peligrosamente opta por publicarla, el corresponsal en Beirut Georg Laschen (Bruno Ganz) de Círculo de engaños (Volker Schlöndorff, 1981), consciente de que se ha convertido en un títere en la transmisión de atrocidades cuyo origen a veces es precisamente el hecho de van a ser reproducidas por los medios de comunicación, opta por no fotografiar los asesinatos cometidos ante él para no convertirse en cómplice.

Ahondando en esta misma línea, casi una década más tarde tres periodistas (dos de ellos fotógrafos, la tercera acompañada de un operador de cámara) se enfrentan en otras tantas películas con una situación en la que es su propia presencia la que provoca el crimen de que son testigos. Se trata de Territorio Comanche (Gerardo Herrero, 1996), El año de las armas, (John Frankenheimer, 1990) y Antes de la lluvia, (Milcho Manchevski, 1994), con conclusiones muy distintas en cada caso. En Territorio Comanche la periodista consigue pese a todo sentirse ajena a lo que sucede ante sus ojos: Laura Riera (Cecilia Dopazo), uno de los personajes más faltos de ética de todos los analizados hasta el momento, está tan ansiosa por conseguir imágenes impactantes, respondan o no a la verdad, que ni siquiera pestañea al ver que como consecuencia directa de que ella esté grabando un reportaje el francotirador que lo protagoniza decida matar a un hombre.

Otra opción es la que propone El año de las armas, en la que la fotógrafa Alison King (Sharon Stone) trata de seguir adelante engañándose a sí misma con la creencia de que el testigo sólo es tal y que su presencia no cambia los hechos sobre los que reporta. La acción del filme se sitúa en Italia en 1978. Las Brigadas Rojas llevan a cabo una política de terror que al periodista norteamericano David Raybourne (Andrew McCarthy) le interesa sólo vagamente, demasiado concentrado en las vicisitudes de su romance con Lia (Valeria Golino) y en la novela que escribe en secreto. Frente a él, Alison es mucho más consciente de lo que sucede a su alrededor y, sin duda, tiene mucha mayor vocación periodística, pero su actitud con respecto a la información con la que trabaja es también la de una pretendida neutralidad que el filme revela como imposible.

"A mucha gente le repele lo que hago. Pero quiero que miren mis fotos y vean lo que yo vi, que sientan lo que yo sentí. Que sean testigos" (00:34:43). De este modo la 
fotógrafa, que sitúa a su cámara entre el mundo y ella misma -al respecto llega incluso a explicar su sensación de que estar parapetada tras ella la protege de la muertepretende ser un testigo imparcial y ajeno de los acontecimientos que discurren ante sus ojos. Pero el hecho de que haya un periodista mirando puede ser en sí mismo el germen de la información, como sucede con la ejecución de la novia del protagonista, expresamente realizada ante Alison con el fin de transmitir al mundo un mensaje sobre cómo tratan a los traidores las Brigadas Rojas (01:42:51). Su creencia de que la cámara que interpone entre su mirada y lo observado funciona a modo de escudo infranqueable, se ve completa e inevitablemente minada por la contundencia de lo ocurrido. Sin embargo permanecerá fiel a su oficio considerando que si las guerras existían antes que los cronistas es ilógico culparlos a ellos de los desmanes irracionales que se producen en las mismas.

Por último, la tercera postura es la que adopta en Antes de la lluvia el reputado fotógrafo internacional y ganador de un Pulitzer, Aleksander Kirkov (Rade Serbedzija), que decide abandonar su trabajo porque se siente culpable del asesinato de un hombre a manos de un miliciano, motivado a su vez por el interés por aportarle al fotógrafo material interesante para sus imágenes. Aleks termina por considerar que es su cámara la autora del crimen que supone además una violación de su presunción de la posibilidad de tomar fotografías desde un territorio neutral (Tangerstad, 2000).

Ya de regreso en Macedonia, Alexander trata de mantenerse al margen de la violencia pero cuando por fin no puede evitar tomar partido y trata de impedir que la hija de su antigua novia sea ajusticiada por sus primos, él mismo se convierte en víctima. Uno de los principales mensajes del filme es la imposibilidad de abstraerse de los efectos generados por la violencia, por muy lejos que una crea vivir de ella. La toma de partido se presenta no sólo como necesaria sino también como inevitable.

\begin{abstract}
¿Es posible tomar partido contra la violencia y el asesinato sin convertirse en víctima o perpetrador de la violencia? ¿Pueden las instituciones religiosas mantenerse apolíticas, resistirse a tomar partido y aun así conservar algún grado de autoridad moral? ¿Se puede superar un odio definido histórica y culturalmente entre distintos grupos étnicos y religiosos para conservar una identidad nacional?5 (Makarushka, 2009: 8).
\end{abstract}

\title{
4. De los caza-exclusivas a los paparazzi
}

Frente a este corresponsal de guerra solitario, un tanto perdido y que en la medida de sus posibilidades trata de ejercer su trabajo desde la honradez aun con pocas perspectivas de éxito, el primer gran estereotipo, cronológicamente hablando, que el cine acuña del fotoperiodista (y en general de los periodistas) va a eludir los dilemas éticos profesionales para directamente lanzarse a la caricatura del truhan simpático y bohemio. Se trata del que hemos denominado "caza-exclusivas", que aparece en los años 30 y que de manera más o menos constante va reapareciendo a lo largo de todo el siglo con matices cada vez más negativos y oscuros.

5 Traducción del autor, en inglés en el original. 


\subsection{El simpático truhan de los años 30}

El primer fotoperiodista de la ficción cinematográfica es egocéntrico, lleva el periodismo en la sangre o, en este caso, tiene una "cámara en lugar de corazón", desprecia profundamente al público al tiempo que está dispuesto a hacer lo que sea para contentarlo -incluyendo mentir, engañar, trapichear o estafar -, está mucho más interesado por las exclusivas que por la verdad y dispuesto a recurrir a cualquier clase de trampa o engaño que le permita obtener una información mejor y dejar en ridículo a sus rivales. Pese a todo este dechado de "virtudes", se trata de un personaje simpático, bohémico y con encanto, no exento de atractivo, en gran medida debido a que las películas de la época en las que aparecen periodistas suelen contar con un tono de comedia que aligera la carga crítica.

Un buen ejemplo podría ser Chris Hunter (Clark Gable) de Sucedió en China, el reportero estrella del Union Newsreel que protagoniza una disparatada comedia protagonizada por dos enviados especiales en el extranjero de sendas agencias que proveen a los noticieros cinematográficos. Su antagonista es Bill Daniels, del Atlas Newsreel, muy similar a él en muchos aspectos. La primera vez que vemos a Hunter "en directo" está jugando a las cartas con varios soldados chinos. Su técnico de sonido, provisto de unos prismáticos, le "sopla" por los cascos las manos de sus rivales de partida. Aparte de ser un probado tramposo, Hunter cumple también con los estereotipos de vestuario de los periodistas de cine de su casta: lleva el sombrero con el ala levantada y va bastante desarreglado. Pero pronto demuestra también que es valiente hasta la imprudencia, sobre todo cuando existe la posibilidad de conseguir unos buenos planos. No en vano su jefe dice de él que "no dejaría su cámara aunque viera ardiendo a su abuela" (00:23:04). En esta ocasión, mientras el resto de sus compañeros corren a ponerse a cubierto durante un ataque aéreo, Hunter persigue a los aviones con su cámara.

Pero si no hay noticias a las que lanzarse imprudentemente, no tiene empacho en inventárselas: la siguiente secuencia nos lo muestra falsificando una escena de bombardeo con un avión de juguete. Hunter se defiende de sus compañeros, que le reprochan el truco, asegurando que no ha distorsionado la realidad sino que sólo "la ha retocado" (00:13:49). En último término la película no condena de manera drástica este modus operandi que le vale primeras páginas y la alegría de su jefe, que no en vano ha gritado al principio del filme "Hunter, entreténgame, emocióname" (00:03:56), justo antes de disponerse a visionar un material que supone que va a tratar sobre "la población civil bombardeada y aviones ametrallando las calles".

A lo largo del filme hay varias escenas en las que en tono de comedia se muestra cómo los periodistas suelen recurrir a las artimañas y los engaños para salirse con la suya, como, por ejemplo, el momento en que Daniels acude disfrazado al despacho del redactor jefe del Union Newsreel para obtener información del paradero de Hunter, la secuencia en que este y su técnico de sonido impresionan a un grupo de indígenas con una proyección cinematográfica o cuando camuflan la cámara en el disfraz del brujo de la tribu.

La idea de que los periodistas están dispuestos a llegar a donde haga falta para conseguir su exclusiva es recurrente. En Ha entrado un fotógrafo (Lloyd Bacon, 1933), Danny Kean (James Cagney) es un gánster reconvertido a fotoperiodista que 
arranca su carrera con la publicación de una fotografía ajena para, más tarde, robar una acreditación para poder asistir a una ejecución en Sing Sing donde introduce, sin permiso, una Leica II atada a su tobillo para obtener imágenes de la ejecución ${ }^{6}$. En esta película se hace explícita la idea de que el fotoperiodista es el escalón más bajo dentro del periodismo amarillista, tal y como le reprocha la estudiante de periodismo Patricia Ellis (Patricia Nolan):

“¿Qué crees que eres? ¿Un periodista? ¿Por qué? Eres lo más bajo del periodismo, un caza-fotos. ¿Para qué crees que te contrató Mr. Grover? Para que pudieras golpear a ancianas y volar caja fuertes y robar fotos de personas inocentes que están tan deprimidas que no pueden ni resistirse. Sólo un rufián, haciendo lo mismo que hiciste siempre" (00:55:29).

Muchos años más tarde Primera Plana (Billy Wilder, 1978) recoge la misma estratagema para introducir cámaras en lugares prohibidos cuando el jefe Walter Burns (Walter Matthau) intenta convencer a su reportero estrella Hildy Johnson (Jack Lemmon) -que está de visita en el periódico para anunciar que lo abandona porque tras casarse va a trabajar de publicista- de que introduzca de tapadillo una cámara atada a su tobillo y con una especie de disparador remoto en forma de pera para fotografiar la ejecución de Williams (Austin Pendleton). Como no logra convencerlo es el novato, recién salido de la facultad y poco espabilado Rudy Keppler (Jon Korkes) quien porta la cámara oculta y asiste más tarde a su jefe en el proceso de toma fotográfica en el que, una vez más, se revela innecesaria la presencia de un profesional específico. La escena en el que un amarillista Walter Burns dirige al prisionero fugitivo para que borre su sonrisa y en su lugar se muestre como un animal acorralado insiste en la línea de argumentación mantenida en este epígrafe según la cual un periodista de película no deja nunca que la realidad le arruine una buena fotografía. Lo mismo ocurre con el cámara de noticieros Bill Allen (William Gargan) de La dama de la prensa (Otto Brower, 1933), mientras que en Divina Gloria (Mervyn LeRoy, 1935), los fotógrafos van un paso más allá y cual "photoshoperos" incipientes llevan la manipulación fotográfica al extremo al crear a partir de la mezcla de diversas imágenes a la inexistente "mujer más bella de América", al modo de la "composografía" realizada por el Evening Graphic en 1925 (Life Magazine, 1950).

\subsection{El periodista amarillista de Sucesos}

Este caza exclusivas que el cine de los años 30 trata con cariño y desde la comedia pronto deviene en un personaje mucho más negativo, el periodista amarillista cuya falta de escrúpulos provoca consecuencias mucho más serias que las anécdotas protagonizadas por sus predecesores cinematográficos. El paradigma de este nuevo personaje, si bien no el primero, es Chuck Tatum (Kirk Douglas) en El Gran Carnaval, el más negro y desencantado de los retratos de periodistas realizados por el

${ }_{6}^{6}$ La escena está inspirada en hechos reales puesto que Tom Howard utilizó una técnica similar para fotografiar la ejecución de la asesina Ruth Snyder para el New York Daily News. 
director vienés. El ansia de Tatum por conseguir una noticia que lo devuelva a la primera fila del periodismo termina por provocar la muerte de Leo Minosa, atrapado en una mina. Antes de que esto suceda, la película va dando numerosos detalles de la enorme capacidad del periodista para dotar a su historia de cuantos más elementos de interés humano sea posible, aunque ello implique no ser totalmente fiel a la verdad. Los efectistas reportajes atraen a una multitud de curiosos que enriquecen a la poco escrupulosa mujer del minero y dan popularidad al periodista. El circo mediático favorece a todo el mundo menos a su protagonista, que enferma a ojos vista a medida que se prolonga su cautiverio, mientras en el exterior proliferan las muestras de afecto hacia él.

\begin{abstract}
"En última instancia, la denuncia más severa del film no apunta al comportamiento aislado de un periodista alienado por el deseo de reconocimiento como Chuck Tatum, sino al hipócrita comportamiento de las miles de personas que se acercan hasta el lugar en el que un hombre atrapado agoniza para vivirlo como una forma más de entretenimiento. La desbocada agresividad y cinismo del reportero, que lo convierten en un prototípico villano fílmico sin paliativos, palidece ante la inhumana mezquindad colectiva de miles de curiosos movidos sólo en apariencia por motivos irreprochables” (Peña, 2013).
\end{abstract}

A finales de siglo XX, Mad City constituye una versión televisiva y modernizada de la misma historia, también con final trágico en este caso. En ambas, además, estos periodistas faltos de ética "crean escuela" con sus prácticas profesionales: Tatum instruye al novato Herbie, mientras que Bracket tiene una alumna excepcional en Laurie, que a la postre demuestra ser aún más despiadada que él ${ }^{7}$.

Un diálogo de El ojo público (Howard Franklin, 1992) sirve de perfecto epítome de la mala opinión del cine sobre los fotoperiodistas de Sucesos: "Espero que no lo tome por un ser humano. Y no cuente con que le haga un favor. ¿Sabe lo que hace un fotógrafo al ver un bebé? Pincharle. Si el bebé llora, la foto vale un dólar más" (00:40:27).

Y además, sin foto, al menos en la prensa sensacionalista, no hay noticia. Siguiendo esta idea podemos ir recorriendo buena parte del argumento de Detrás de la noticia (Ron Howard, 1994) que, dentro de lo que cabe, presenta la cara buena del periodismo sensacionalista, sobre todo si la comparamos con los otros títulos que hemos mencionado hasta aquí. Desde la primera reunión para decidir los temas del día y su enfoque queda clara la importancia que para el sensacionalista The Sun tiene haya o no foto. El accidente del metro, del que hay imágenes, se perfila como tema del día hasta que aparece otro mejor que, además, tiene posible instantánea. Pero el jefe de local. Henry Hackett (Michael Keaton) duda del enfoque y él sabe mejor que nadie que si no hay foto no hay noticia, de ahí que envíe a conseguirla a Robin (Amelia Campbell) la más novata y menos diestra de sus fotógrafos que, contra todo

\footnotetext{
Aunque se sale del tema de este artículo, cabe apuntar que las periodistas suelen ser mucho más despiadadas y faltas de ética que sus compañeros varones, tal y como he estudiado a lo largo de mi tesis doctoral sobre la imagen de las periodistas en el cine de los años 90 (Osorio, 2009).
} 
pronóstico, la consigue. Afortunadamente, en el ínterin Hackett ha logrado imponer su criterio periodístico al mucho más empresarial de su jefa Alicia Clark (Glenn Close) (Osorio, 2012).

Se trata, en suma, del retrato de un periodismo que ahonda en los elementos más sensacionalistas de la noticia y cuyas consecuencias son en general trágicas para los involucrados. El carácter impactante de la fotografía importa más que la realidad y el cine mira con menos simpatía que en sus orígenes a estos periodistas poco escrupulosos con la verdad y ansiosos de primicias impactantes.

\subsection{Los fotógrafos de sociedad}

Finalizamos este recorrido con la figura de los fotógrafos de sociedad, cuyo nombre, como es ya bien sabido, procede precisamente del cine y más concretamente del personaje Paparazzo (Walter Santeso) de la Dolce Vita (Federico Fellini, 1960), bautizado así por un compañero de clase del director de la película. Que no tuvieran nombre propio no quiere decir sin embargo que no existieran antes. En Historias de Filadelfia (George Cukor, 1940), James Stewart interpreta al escritor frustrado Macaulay Connor, que trabaja como cronista de sociedad y que acompañado por la ácida y realista fotógrafa Elizabeth Imbrie (Ruth Hussey) va a cubrir la segunda boda de la joven de alta sociedad Tracy Lord (Katherine Hepburn. La película tiene un remake posterior datado en 1956 y dirigido por Charles Walters, Alta sociedad, en el que Celeste Holm da vida a Liz Imbrie En ninguna de las dos versiones Imbrie se hace muchas ilusiones sobre su propia importancia. Cuando el jefe de ambos les pregunta si lo aborrecen ella contesta: "No puedo permitirme aborrecer a nadie. Sólo soy una fotógrafa" (00:10:06). Imbrie y Connor son unos intrusos y todo el mundo en la casa odia su presencia pero ambos mantienen cierta dimensión humana que se pierde por completo en la agresiva masa de Paparazzo y sus amigos en La Dolce Vita, desprovistos de cualquier identidad, motor o deseo que no sea otro que conseguir una foto de la actriz o el actor de turno, normalmente sin que medie su consentimiento.

Si la imagen pública de los periodistas del corazón en general y de los paparazzi en particular nunca fue demasiado buena, podemos observar que va empeorando hasta alcanzar un punto culminante en el aborrecimiento por parte del público en los años 90 con su implicación en la muerte de Lady Di. De hecho, en 1998 se estrenaron dos películas tituladas precisamente Paparazzi, una francesa (Alain Berberian, 1998) y otra italiana (Neri Parenti, 1998), con muchos famosos entre el casting y una visión no demasiado encomiable acerca del trabajo de los fotógrafos de sociedad que constituyen el escalafón más deleznable del retrato cinematográfico de los periodistas.

\section{Conclusiones}

El retrato robot del fotoperiodista del siglo XX es el de un fotógrafo blanco, de mediana edad que trabaja sobre todo para medios escritos, fundamentalmente cubriendo información internacional o de sucesos. No es un personaje demasiado heroico ni exitoso y oscila entre la perplejidad y el desmoronamiento de los ideales del enviado especial a países del Tercer Mundo hasta la completa falta de moralidad del fotógrafo amarillista sólo preocupado de conseguir la mejor foto posible, un personaje que 
el cine de los años 30 contempla con cierta simpatía y camaradería pero sobre el que se va haciendo más crítico a medida que pasan los años, hasta terminar por retratarlo como un personaje amoral, molesto e incluso en ocasiones dañino. Ninguna película de las analizadas muestra el trabajo del fotógrafo o del operador como una tarea especializada, sino que en la mayoría de ellas se desliza la idea de que los roles del reportero y del fotógrafo son totalmente intercambiables, al tiempo que son varias las películas donde la captura de imágenes es una tarea que se asigna al novato recién llegado, lo que refuerza la idea de que la fotografía periodística no requiere una cualificación especial para su ejercicio.

En definitiva, el cine no ha retratado a los fotoperiodistas de una manera más positiva que al resto de sus colegas en tareas informativas. Si bien el retrato más amable es el ya mencionado del corresponsal de guerra, en el fondo las películas que lo convierten en protagonista no hacen sino poner de manifiesto la incapacidad de los medios de comunicación en general y de los periodistas en particular de convertirse en fieles reflejos e imparciales relatores de los acontecimientos, cuestionando así el papel del cuarto poder en las sociedades democráticas.

\section{Referencias bibliográficas}

ARANGO, Mónica (2011). Las representaciones sociales del periodista en cine relatos literarios y cinco relatos cinematográficos contemporáneos: 1995-2010. Maizales: Universidad de Maizales.

BEZUNARTEA, Ofa; CANTALAPIEDRA, María José; COCA, César et al . (2007). Periodistas de cine y de ética. En: Ámbitos, nº 16, pp. 329-393.

BEZUNARTEA, Ofa; CANTALAPIEDRA, María José; COCA, César et al . (2007). Si hay sangre, hay noticia: recetas cinematográficas para el éxito periodístico. En: Palabra Clave, vol. 10, $\mathrm{n}^{\mathrm{O}}$ 2, pp. 61-74.

BEZUNARTEA, Ofa; CANTALAPIEDRA, María José; COCA, César et al. (2008) ...So What? She's A Newspaperman and She's Pretty. Women Journalists in the Cinema. En: Zer, vol. 13, n 25, pp. 221-242.

BEZUNARTEA, Ofa; CANTALAPIEDRA, María José; COCA, César et al . (2008). Divismo y narcisismo de los periodistas en el cine. Textual \& Visual Media: revista de la Sociedad Española de Periodística, n 1, pp. 107-120.

BEZUNARTEA, Ofa; CANTALAPIEDRA, María José; COCA, César et al . (2010). $\mathrm{El}$ perfil de los periodistas en el cine: tópicos agigantados. En: Intercom - Revista Brasileira de Ciências da Comunicaçao, vol. 33, n 1, pp. 145-167.

BEZUNARTEA, Ofa; CANTALAPIEDRA, María José; GENAUT, Aingeru. (2010). Vivir y relatar la historia: la imagen de los corresponsales de guerra en el cine, www.revistalatinacs.org/10SLCS/actas_2010/aingeru.pdf, [5 Enero 2015].

CASTÁN, Clara (2012). Aproximación a la ética periodística en la ficción cinematográfica. Zaragoza: Universidad de Zaragoza.

CASTELLANO, Roberto (1994). El periodista en el cine. Salamanca: Universidad Pontificia de Salamanca. 
EGUREN, Carlos Javier (2013). El cuarto poder ante la cámara. San Cristóbal de La Laguna: Universidad de La Laguna.

EGUREN, Carlos Javier (2013). El periodista mentiroso en el cine. Explorando dos ejemplos: El precio de la verdad y El reportero de la Calle 42. Universidad de la Laguna: V Congreso Internacional Latina de Comunicación Social.

EHRLICH, Mathew C.; SALTZMAN, Joe (2015). Heroes and Scoundrels: The Image of the Journalist in Popular Culture (The History of Communication). University of Illinois Press.

FUENTEFRÍA, David (2010). Ética personal y relación entre poder político y medios de comunciación en el cine del siglo XX. In: II Congreso Internaciona Latina de Comunicación Social. La Laguna: Universidad La Laguna.

GARCÍA DE LUCAS, Virginia; RODRÍGUEZ, Eduardo; SALES Javier (2006). Cine entre líneas. Periodistas en la pantalla. Valladolid: 51 Semana Internacional de Cine.

GHIGLIONE, Loren (1991). The American Journalist: Fiction Versus Fact [online]. Available from World Wide Web: http://www.ijpc.org/ghiglione.htm, [Accessed 28 Julio 2015].

GOOD, Howard (1998). Girl Reporter: Gender, Journalism, and the Movies. Scarecrow: Lanham, MD.

HART, Joy L. (2008). Sex Role Stereotypes in the Media. En: International Encyclopedia of Communication, www.communicationencyclopedia.com, [28/07/2015].

HERMAN, Sarah (2005). Hacks, heels and Hollywood. How accurately do recent film portrayals of women journalists reflect the working world of their real-life counterparts? BA (HONS): Multi-Media Journalism.

HERNÁNDEZ OSORIO, Carlos (2010). La cámara "tras bastidores": cuatro casos para abordar el periodismo en el cine. En: Filo de Palabra. Una publicación de los docentes de Comunicación Social y Periodismo. Universidad de Maizales, pp. 18-25.

LAVIANA, Juan Carlos (1996). Los chicos de la prensa. Madrid: Nikel Odeon.

MAKARUSHKA, Irena (2009). Religion, Ethnicity and Violence in Before the Rain. http://www.manchevski.com/docs/10_makarushka_religion_violence.pdf, [28/07/2015].

MARTÍNEZ-SALANOVA, Enrique (2011). Periodismo y medios de comunicación en el cine, http://www.uhu.es/cine.educacion/cineyeducacion/periodismo.htm, [12/07/2013].

MCDANIEL, Kyle Ross (2007). Reviewing the image of the photojournalist in film: How ethical dilemmas shape stereotypes of the on-screen press photographer in motion pictures from 1954 to 2006. Columbia: University of Missouri.

MCNAIR, Brian (2010). Journalists in film. Heroes and Villains. Edimburgh: Edimburght University Press.

MÍNGUEZ, Luis (2012). Periodistas de cine. El cuarto poder en el séptimo arte. Madrid: T\&B Editores.

MOBERG, Virgil Boyd (1995). Foreign correspondent films: A form for "knowing” America. Florida: University of South Florida.

MORENO, Ignacio (2012). Postfeminismos: representaciones de género en la cultura popular neoliberal. Madrid: Universidad Complutense de Madrid. 
NESS, Richard R. (1997). From Headline Hunter to Superman. A journalist filmography. Lanham (Maryland): Sarecrow Press.

OSORIO, Olga (2009). La imagen de la periodista profesional en el cine de ficción de 1990 a 1999. A Coruña: Universidade da Coruña.

OSORIO, Olga (2012). Alicia Clark o la jefa que nadie querría tener (Detrás de la noticia). https://periodistasdecine.wordpress.com/2012/10/16/alicia-clark-o-lajefa-que-nadie-querria-tener-the-paper/, [16/07/2015].

OSORIO, Olga (2014). Despersonalización de los medios, poder y guerras de audiencia en el retrato del periodismo en el cine de los años 90. En: Estudios sobre el Mensaje Periodístico, vol 20, n 2, pp.789-804.

PAREJO, Nekane (2009). La mirada del reportero de guerra en el cine. En: Actas del I Congreso Internacional Latina de Comunicación Social. La Laguna: Universidad de La Laguna.

PEÑA, Simón (2012). Primera plana de Billy Wilder: La nostalgia de los periodistas en el exilio. En: Estudios sobre el Mensaje Periodístico, vol 18, n 2, pp.907-924.

PEÑA, Simón (2014). El reportero Billie Wilder. El retrato ácido y nostálgico del periodismo en El Gran Carnaval y Primera Plana. Comunicación Social. Ediciones y publicaciones.

PEÑA, Simón Pablo (2011). Caballeros de la prensa. El periodismo en el cine de Billy Wilder. Leioa: Universidad del País Vasco.

PÉREZ ACUÑA, Beatriz (coord.) (2013). El periodista en imágenes de cine. Madrid: Visión Libros.

REQUEIJO, Paula (2013). El profesional de los medios en el cine de los últimos años. En: Revista de Comunicación Vivat Academia, pp. 54-79.

ROBARDS, Brooks (1990). Newshounds and Sob Sisters: The Journalist Goes to Hollywood. En: Beyond the stars. Studies in American Popular Film. Volume. 1. Stock Characters in American Popular Film, Bowling Green: Bowling Green State University Popular Press, pp. 131-145.

SALTZMAN, Joe (2003). Sob Sisters: The Image of the Female Journalist in Popular Culture. https://www.ijpc.org/uploads/files/sobsessay.pdf, [27/07/2015].

SCHINDLER J.R.; PAUL E. (1996). Journalism Movies, http://psacot.typepad.com/ ps_a_column_on_things/journalism-movies.html, [27/07/2015].

TANGERSTAD, Erik (2000). Before the Rain - After the War? The Narrative Structure of a Feature Film and its Different Receptions. En: Rethinking History, vol $4, n^{\circ} 2$, pp. 175-182.

TELLO DIAZ, Lucía (2014). Los periodistas en el cine de Almodóvar. En: Zer vol 19, no 37, pp. 86-106.

UNIVERSITY OF CALIFORNIA, BERKELEY (1996-2009). Media Resources Center. http://www.lib.berkeley.edu/MRC/womenbib.html\#books, [27/07/2015].

VON TUNZELMANN, Alex (2009). Salvador: Oliver Stone, lose the fast and loose approach. http://www.theguardian.com/film/2009/apr/08/salvador-oliver-stone, [14/07/2015]. 